\title{
Quantification of guanosine tetraphosphate and other nucleotides in plants and algae using stable isotope-labelled internal standards.
}

Julia Bartoli ${ }^{1}$, Sylvie Citerne ${ }^{2}$, Gregory Mouille ${ }^{2}$, Emmanuelle Bouveret $^{3}$ and *Ben Field ${ }^{4}$

\footnotetext{
${ }^{1}$ Aix Marseille Univ CNRS, LISM, UMR 7255, IMM FR 3479, 31 Chemin Joseph Aiguier, 13009, Marseille, France

${ }^{2}$ Institut Jean-Pierre Bourgin, INRAE, AgroParisTech, Université Paris-Saclay, 78000, Versailles, France

${ }^{3}$ Stress Adaptation and Metabolism in Enterobacteriae Unit, Department of Microbiology, Institut Pasteur, Paris 75015, France

${ }^{4}$ Aix Marseille Univ, CEA, CNRS, UMR 7265 BIAM, 13009 Marseille, France

*Corresponding author: ben.field@univ-amu.fr
} 


\section{Abstract}

Guanosine tetraphosphate (G4P) and guanosine pentaphosphate (G5P) are signalling nucleotides found in bacteria and photosynthetic eukaryotes that are implicated in a wide-range of processes including stress acclimation, developmental transitions and growth control. Measurements of G4P/G5P levels are essential for studying the diverse roles of these nucleotides. However, G4P/G5P quantification is particularly challenging in plants and algae due to lower cellular concentrations, compartmentation and high metabolic complexity. Despite recent advances the speed and accuracy of G4P quantification in plants and algae can still be improved. Here, we report a new approach for rapid and accurate G4P quantification, applicable to plants and algae, which relies on the use of synthesised stable isotopelabelled as internal standards. We anticipate that this approach will accelerate research into the function of G4P signaling in plants, algae and other organisms.

\section{Introduction}

Guanosine tetraphosphate (G4P) and guanosine pentaphosphate (G5P) are signalling nucleotides found in bacteria and photosynthetic eukaryotes that are implicated in a wide-range of processes including stress acclimation, differentiation and growth control (Field, 2018; Ronneau and Hallez, 2019). The accurate quantification of G4P and G5P is critical for studying the role of these signalling nucleotides. However, extraction and quantification of G4P/G5P can be challenging due to the vulnerability of these nucleotides to enzymatic and chemical degradation, their low basal concentrations, and high polarity. In bacteria G4P and G5P are routinely measured by radiographic detection on TLC plates after extraction from cells that have been globally labelled with P32, by growing them for several generations in the presence of 32P-labelled pyrophosphate. Ion exchange HPLC methods with UV detection have also been developed for the quantification of G4P and G5P in bacteria, and these methods have the advantage of allowing the simultaneous quantification of other nucleotides (Buckstein et al., 2008; Varik et al., 2017). More recently, a method using hydrophilic-interaction chromatography (HILIC) with mass spectrometry (MS) based detection and identification was also reported for bacteria (Zborníková et al., 2019). The quantification of other nucleotides by these HPLC-based methods provides valuable information because G4P/G5P synthesis consumes GDP/GTP and ATP, and because G4P/G5P can function by directly inhibiting GTP biosynthesis (Liu et al., 2015).

G4P/G5P quantification is yet more challenging in plants and algae due to lower concentrations (Takahashi et al., 2004), compartmentation and the high metabolic complexity of these organisms. The first report of G4P and G5P in plants and algae used ion exchange HPLC with UV detection (Takahashi et al., 2004). However, this approach was not widely used- most likely because it requires large amounts of starting material, and a complex extraction procedure. A major step forward for measuring G4P in plants came with the report of a reverse phase HPLC tandem mass spectrometry (MS/MS) based method for G4P quantification that required minimal amounts of starting material and involved a simple solid-phase extraction (SPE) based enrichment step (Ihara et al., 2015). HPLC-MS/MS based quantification allows for greater sensitivity and specificity than HPLC-UV methods. However, a drawback of the lhara et al. method is that for the calculation of the starting G4P concentration the extract must be split into two 
aliquots and one aliquot spiked with a known quantity of authentic G4P as an internal standard. This approach corrects for matrix effects, and to some extent for sample loss. However, it is time-consuming, and quantification is vulnerable to inaccuracies caused by the degradation of endogenous G4P before the addition of the internal standard and to differences in treatment between the spiked and un-spiked aliquots. Analyte loss and matrix effects can be overcome using stable-isotope labelled internal standards. Along these lines a method for G4P/G5P quantification in bacteria using metabolically labelled cell extracts and ion exchange HPLC-MS/MS detection was recently described in bacteria (Patacq et al., 2018). Here we build on this previous work and report a new approach for more rapid and accurate G4P quantification in plants and algae using synthesised stable isotope-labelled internal standards. Our approach also allows the simultaneous quantification of GTP, and could be extended to other nucleotides. 


\section{Materials and Methods}

\section{Production and purification of Rel $_{\text {seq }}$ and GppA enzymes}

Rel $_{\text {seq }}$ (1-385)-6His and 6His-TEV-GppA were expressed in E. coli, using plasmids pBAD-Relseq1-385-6His (Mechold et al., 2013) and pET-6his_tev-GppA , which was obtained by cloning the gppA ORF between the EcoRI and Xhol restriction sites of the plasmid pEB1188 (Wahl et al., 2011). The proteins were purified by affinity chromatography on cobalt resin as previously described (My et al., 2013) (Supplementary Fig. 1). Final concentrations of Relseq(1-385) and GppA proteins were $4.8 \mathrm{mg}^{\mathrm{m} \mathrm{m}^{-1} \text { and }}$ $1.4 \mathrm{mg} \cdot \mathrm{ml}^{-1}$ respectively, in the purification buffer with $40 \%$ glycerol.

\section{In vitro 13C-G5P and 13C-G4P synthesis}

For the synthesis of G5P a reaction containing $2.5 \mathrm{uM}$ Relseq, $2.5 \mathrm{mM}$ ATP, $5 \mathrm{mM} 13 \mathrm{C}-\mathrm{GTP}\left({ }^{13} \mathrm{C}_{10} \mathrm{GTP}\right.$ sodium salt; reference 710687, Sigma-Aldrich), $10 \mathrm{mM}$ Tris-Cl pH 8.0, $100 \mathrm{mM} \mathrm{NaCl}$ and $15 \mathrm{mM} \mathrm{MgCl}$ was incubated at $37^{\circ} \mathrm{C}$ for $2 \mathrm{hrs}$. The reaction mixture was then passed through a spin filter column (Nanosep 10K Omega, Pall Corporation) to remove enzyme before separation of the reaction products by HPLC. For the synthesis of G4P the same reaction as above was performed, and then GppA was added at a concentration of $1.7 \mathrm{uM}$ and the reaction incubated for a further $30 \mathrm{~min}$ at $37^{\circ} \mathrm{C}$ before filtration and separation by HPLC.

\section{HPLC separation and purification of 13C-G5P and 13C-G4P}

An Agilent 1260 Infinity HPLC system with a SAX $5 \mu \mathrm{m} \mathrm{4.6 \times 250} \mathrm{mm} \mathrm{Waters} \mathrm{Spherisorb} \mathrm{analytical} \mathrm{column}$ was used to separate samples over 35 min using a gradient of solvent $A\left(\mathrm{KH}_{2} \mathrm{PO}_{4} 50 \mathrm{mM} \mathrm{pH} 3.4\right)$ and solvent $B\left(K_{2} \mathrm{PO}_{4} 1 \mathrm{M} \mathrm{pH} 3.4\right)$ at a flow rate of $1 \mathrm{ml} \mathrm{min}^{-1}$. The gradient consisted of $5 \mathrm{~min}, 100 \% \mathrm{~A} ; 10$ $\min , 70 \%$ A; $19 \mathrm{~min}, 45 \%$ A; $20 \mathrm{~min}, 25 \%$ A; $30 \mathrm{~min}, 0 \% \mathrm{~A} ; 35 \mathrm{~min}, 0 \% \mathrm{~A}$. Nucleotides were identified by absorbance at $254 \mathrm{~nm}$, and selected nucleotides were collected. Collected nucleotides were diluted in formic acid (1M final concentration), loaded onto Oasis WAX SPE cartridges pre-equilibrated with $50 \mathrm{mM}$ ammonium acetate, washed with $50 \mathrm{mM}$ ammonium acetate and then methanol, and then eluted in a mixture of methanol/water/ $\mathrm{NH}_{4} \mathrm{OH}$ (20:70:10). Eluates were lyophilised and then resuspended in $5 \mathrm{mM}$ Tris- $\mathrm{Cl}$ pH 8.0 before verification by HPLC and HPLC-MS/MS. Dose response curves indicated a linear relationship over a wide range of concentrations for G4P (as observed previously), GTP and their stableisotope labelled analogues.

\section{Micororganism and plant growth}

Escherichia coli MG1655 (WT) and MG1655 $\Delta$ relA spoT207::cat (ppGpp ${ }^{\circ}$ ) (Wahl et al., 2011) were grown in Luria Bertani broth at $37^{\circ} \mathrm{C}$ until an $\mathrm{OD}_{600}$ of $~ 2$. MG1655 pALS10 (Svitil et al., 1993) was grown until an $\mathrm{OD}_{600}$ of 1.5 and then induced for $1 \mathrm{hr} 15 \mathrm{~min}$ with $1 \mathrm{mM}$ IPTG. Cells were aliquoted, washed in 1 volume of cold TBS, and pellets frozen at $-80^{\circ} \mathrm{C}$ before nucleotide extraction.

Chlamydomonas reinhardtii strain CC-4533 (Li et al., 2016) was grown in TAP medium at $22^{\circ} \mathrm{C}$ with continuous illumination and agitation at $120 \mathrm{rpm}$. After $48 \mathrm{hrs}$ when cells had reached a density of around $5 \times 10^{6}$ cells $\mathrm{ml}^{-1}$ cells were divided and either cultivated in the light or darkness at $22^{\circ} \mathrm{C}$ with 
agitation at $120 \mathrm{rpm} .1 .1 \times 10^{8}$ cells were then harvested by centrifugation at $4^{\circ} \mathrm{C}$ and stored at $-80^{\circ} \mathrm{C}$ until extraction.

Arabidopsis thaliana Col-0 (WT) and OX:RSH3.1 plants (Sugliani et al., 2016) were grown in soil under a 16-h-light/8-h-dark photoperiod at $18 / 22^{\circ} \mathrm{C}$ with $115 \mu \mathrm{mol} \mathrm{m} \mathrm{m}^{-2} \mathrm{~s}^{-1}$ PAR fluorescent lighting. After 4 weeks rosette leaves were harvested and ground to a fine powder in liquid $\mathrm{N}_{2}$ and then stored at $-80^{\circ} \mathrm{C}$ until extraction.

\section{GTP and G4P extraction from bacteria, plants and algae.}

Nucleotides were extracted using a modified version of a previously reported method (Ihara et al., 2015). Samples were mixed with $3 \mathrm{ml}$ of cold $2 \mathrm{M}$ formic acid containing stable-isotope labelled nucleotides (125 pmoles 13C-GTP, 12.5 pmoles 13C-G4P) and incubated for 30 minutes on ice. $3 \mathrm{ml}$ of $50 \mathrm{mM}$ ammonium acetate at $\mathrm{pH} 4.5$ was then added, samples were centrifuged at $5000 \mathrm{rpm}$ at $4^{\circ} \mathrm{C}$ for $10 \mathrm{~min}$ and supernatants loaded onto Oasis WAX SPE cartridges pre-equilibrated with $1 \mathrm{ml}$ methanol then $1 \mathrm{ml} 50$ $\mathrm{mM}$ ammonium acetate $\mathrm{pH} 4.5$ at $4^{\circ} \mathrm{C}$. After all the sample was loaded, the cartridge was washed with 1 $\mathrm{ml} 50 \mathrm{mM}$ ammonium acetate $\mathrm{pH} 4.5$ and then $1 \mathrm{ml}$ methanol, and then eluted in 1-2 $\mathrm{ml}$ of a mixture of methanol/water/ $\mathrm{NH}_{4} \mathrm{OH}$ (20:70:10). Water was added to reduce methanol to $10 \%$ and eluates were lyophilised and resuspended in $200 \mu \mathrm{l}$ water before analysis by HPLC-MS/MS.

\section{Analysis by HPLC-MS/MS}

Extracts were filtered, and analyzed using a Waters Acquity ultra performance liquid chromatograph coupled to a Waters Xevo Triple quadrupole mass spectrometer TQS (UPLC-ESI-MS/MS). $1 \mu$ l of extract was separated on a reverse-phase column (Uptisphere C18 UP3HDO, $100 \times 2.1 \mathrm{~mm}, 3 \mu \mathrm{m}$ particle size; Interchim, France) using a flow rate of $0.3 \mathrm{ml} \mathrm{min}^{-1}$ and a binary gradient: (A) $8 \mathrm{mM}$ DMHA with $80 \mu \mathrm{l}$ $\mathrm{AcOH} / 500 \mathrm{ml}$ water and (B) acetonitrile, the column temperature was $40{ }^{\circ} \mathrm{C}$. We used the following binary gradient: 0 min, $100 \%$ A; $10 \mathrm{~min}, 60 \%$ A; $10.5 \mathrm{~min}, 100 \%$ A; $20 \mathrm{~min}, 100 \%$ A. Mass spectrometry was conducted in electrospray and Multiple Reaction Monitoring scanning mode (MRM mode), in negative ion mode. Relevant instrumental parameters were set as follows: capillary $1.5 \mathrm{kV}$ (negative mode), source block and desolvation gas temperatures $130{ }^{\circ} \mathrm{C}$ and $500^{\circ} \mathrm{C}$, respectively. Nitrogen was used to assist the cone and desolvation ( $150 \mathrm{~L} \mathrm{~h}^{-1}$ and $800 \mathrm{~L} \mathrm{~h}^{-1}$, respectively), argon was used as the collision gas at a flow of $0.18 \mathrm{ml} \mathrm{min}^{-1}$. Multiple reaction conditions and fragment ions selected for quantification are shown in Table 1. Limits of detection (LOD) and quantification (LOQ) were calculated as the nucleotide concentration that could be detected in $150 \mathrm{mg}$ of Arabidopsis tissue with a signal to noise ratio above 3 or 10 , respectively (Table 1 ). 


\section{Results}

Stable-isotope labelled internal standards are considered the gold-standard for the quantification of small metabolites due to their ability to compensate for matrix effects and analyte loss (Stokvis et al., 2005). We therefore set up a method to synthesise stable-isotope labelled G5P and G4P from the widely available stable-isotope labelled GTP. We produced the bacterial enzymes Rel $_{\text {seq }}$, which synthesises G5P, and GppA, which hydrolyses G5P to G4P (see Material and Methods and Supplementary Fig. 1). We then carried out G4P and G5P in vitro synthesis reactions as previously described (Corrigan et al., 2016;

Mechold et al., 2013) but using totally labelled guanosine $-{ }^{13} \mathrm{C}_{10} 5$ ?]-triphosphate (13C-GTP) as a substrate in order to produce $13 \mathrm{C}$ labelled G5P and G4P (Fig 1A). We separated the reaction products by ion exchange HPLC and isolated 13C-G5P and 13C-G4P (Figure 1B). HPLC-MS/MS analysis of the isolated 13CG4P and 13C-G5P showed the expected +10 mass shift for the $[\mathrm{M}-\mathrm{H}]$ ] parent ion compared to the nonlabelled compounds, and the same characteristic fragmentation of the parent ion into daughter ions (Fig. 1C).

A

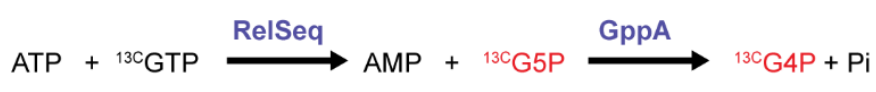

B
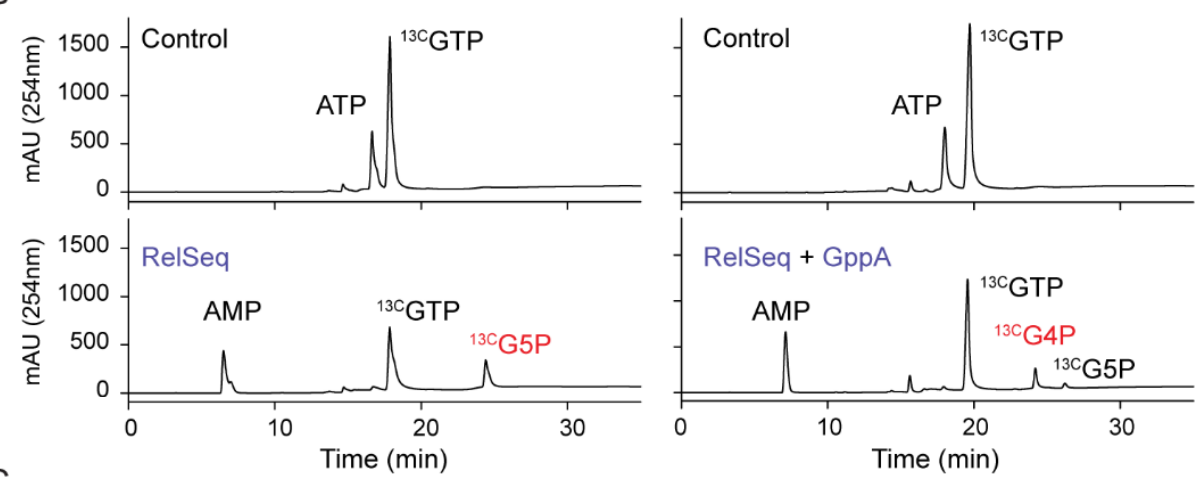

C
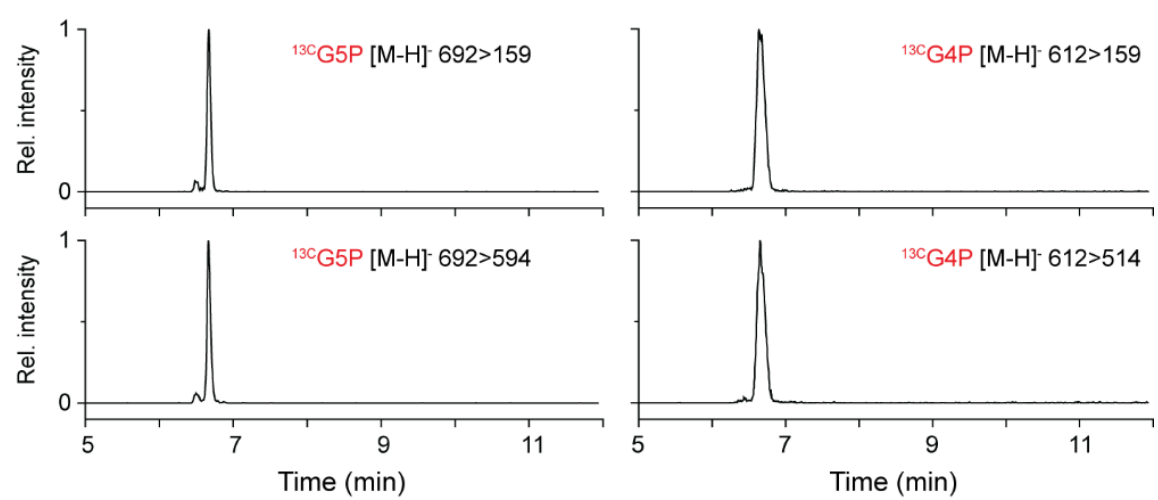

Figure 1. Synthesis and isolation of stable-isotope labelled G4P and G5P. (A) Outline of reaction scheme for the synthesis of isotope-labelled nucleotides. (B) Separation of reaction products by ion-exchange HPLC from control reactions where no enzyme was added, and from reactions where the indicated enzymes were included. (C) Validation of isolated nucleotides by detection of daughter ions following the collision induced ionization of 13C-G5P and 13C-G4P [M-H]- parental ions. 
We next confirmed that the stable isotope labelled G4P could be used to quantify endogenous unlabelled G4P levels in bacteria. We adapted the extraction procedure of lhara et al. (2015) by adding stable-isotope labelled G4P to the extraction buffer before mixing with the biological sample, and by continuing to the SPE enrichment step without splitting each sample (Fig. 2A). This approach allowed us to use the 13C-G4P internal standard signal to account for endogenous G4P loss during the extraction procedure and matrix effects such as ion suppression during MS/MS analysis. Using this method, we calculated endogenous G4P concentrations in wild-type Escherichia coli, a G4P/G5P null mutant, and in a strain containing an inducible G4P synthase expressed from plasmid pALS10 (Svitil et al., 1993)(Fig. 2B). Concentrations in the wild-type $\left(24.8 \pm 2.6 \mathrm{SE} \mathrm{pmol} \mathrm{OD}_{600}{ }^{-1}\right)$ were within the range of steady-state levels previously reported (3-40 pmol per OD) (Hernandez and Bremer, 1991; Maciag et al., 2010; Macvanin et al., 2000; Murray and Bremer, 1996; Slomińska et al., 1999) although higher levels are sometimes detected (Ihara et al., 2015). No G4P was detected in the G4P/G5P null mutant that lacks all G4P/G5P synthetase activity, and three-fold higher levels of G4P were measured in the strain expressing a G4P

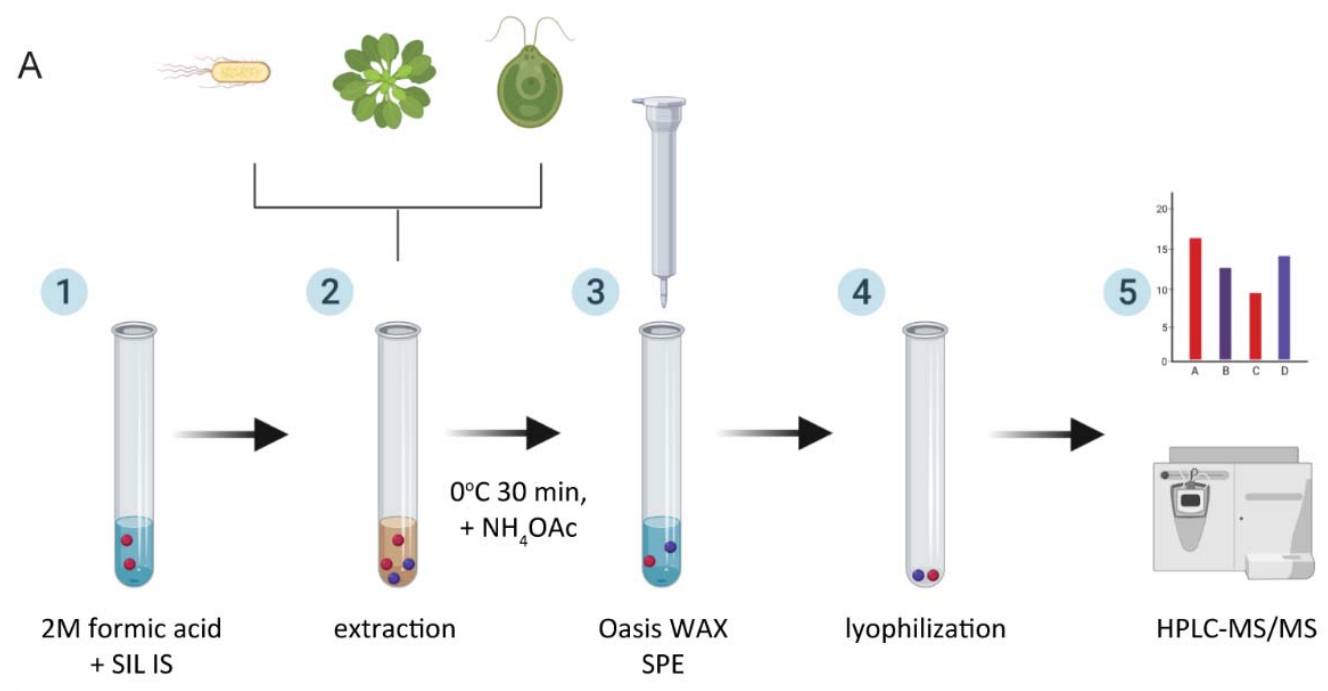

B

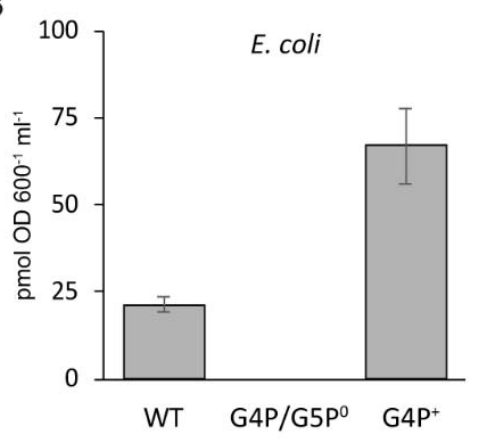

Figure 2. A procedure for the quantification of nucleotides in bacteria, plants and algae. (A) Outline of the extraction procedure with stable-isotope label internal standards. 1, formic acid containing stable-isotope labeled (SIL) internal standards (IS)(red circles) is prepared; 2 , biological samples containing unlabeled endogenous nucleotides (violet circles) are added; 3 , nucleotides are enriched using an Oasis weak-anion exchange (WAX) solid phase extraction (SPE) cartridge; 4, nucleotides are eluted and lyophilized; and 5, nucleotides are injected into an HPLC-MS/MS system for analysis and quantification. (B) The procedure for the extraction and quantification of G4P was validated on late exponential phase bacterial cells from a wild type strain (WT), a strain lacking G4P and G5P (G4P/G5P ), and a strain over-accumulating G4P $\left(\mathrm{G} 4 \mathrm{P}^{+}\right)$. Means $+/$- SE are indicated, $n=4$ biological replicates 
synthase.

Once we had established that the method worked in bacteria, we then tested whether stable-isotope labelled internal standards could be used to simultaneously quantify the endogenous levels of GTP and G4P in the more challenging tissues of a plant. Using stable-isotope labelled GTP and G4P internal standards, we were able to quantify endogenous GTP and G4P levels in leaves of wild-type Arabidopsis and plants overexpressing the G4P/G5P synthetase RSH3 (OX:RSH3.1) (Fig. 3A). GTP levels measured in wild-type plants $\left(7.8 \pm 0.6 \mathrm{nmol} \mathrm{g}^{-1}\right)$ were similar to those previously reported in Arabidopsis $(9-16 \mathrm{nmol}$ $\mathrm{g}^{-1}$ ) using ion exchange HPLC with UV detection (Hung et al., 2004; Yang et al., 2015). G4P levels were also similar to those that we previously determined in wild-type $\left(28.7 \pm 2.2 \mathrm{pmol} \mathrm{g}^{-1}\right.$ versus $21.7 \pm 3.4$ pmol g$\left.{ }^{-1}\right)$ and OX:RSH3.1 plants that overproduce G4P (236.8 $\pm 47.4 \mathrm{pmol} \mathrm{g}^{-1}$ versus $\left.147.7 \pm 7.4 \mathrm{pmol} \mathrm{g}^{-1}\right)$ (Sugliani et al., 2016).

A

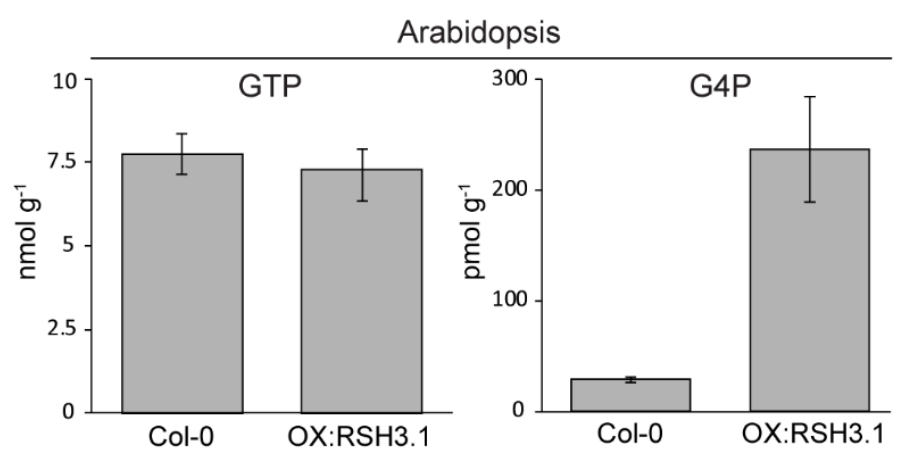

B

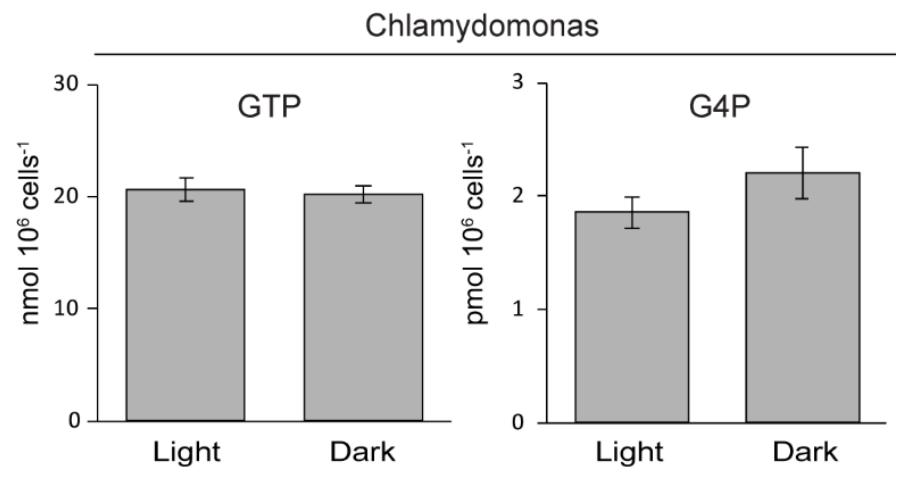

Figure 3. Quantification of GTP and G4P in plants and algae. (A) GTP and G4P were quantified in the leaves of 4 week old Arabidopsis plants using 13-GTP and 13C-G4P internal standards. Means $+/-$ SE are indicated, $n=4$ biological replicates. (B) GTP and G4P were quantified in Chlamydomonas cells grown under normal conditions (light) or transferred to darkness for $1 \mathrm{hr}$ (dark) using using 13-GTP and 13C-G4P internal standards. Means +/SE are indicated, $n=4$ biological replicates.

To determine whether this stable-isotope quantification approach could be applied more widely we also simultaneously quantified GTP and G4P in cells of the model green alga Chlamydomonas reinhardtii grown under normal conditions or after transfer to darkness for $1 \mathrm{hr}$ (Fig. 3B). Both nucleotides were readily detected, and we observed a small increase in G4P levels in response to dark treatment $(P=0.1$, Wilcoxon test, $n=4)$. The nucleotide concentrations could not be compared to published concentrations 
because we are not aware of previous reports of GTP or G4P measurements in comparable units in Chlamydomonas.

The 13C-G5P that we produced could be potentially used for quantification, and indeed low amounts of G5P were previously observed in plants (Takahashi et al., 2004). However, in preliminary tests we found G5P detection in plant and algal extracts to be unreliable, suggesting that further optimisation is required. Previously it was also observed that an organic solvent based nucleotide extraction procedure caused the conversion of G5P into G4P, therefore affecting the accuracy of endogenous G4P quantification (Patacq et al., 2018). However, this may be specific to the extraction procedure because we did not observe conversion of 13C-G5P into 13C-G4P following the formic acid-based extraction procedure we describe in this work without addition of biological material.

\section{Discussion}

We describe a stable-isotope internal standard based method for the extraction and quantification of G4P and GTP in plants and algae. Due to the use of stable-isotope internal standards this method is more rapid and accurate than previous methods for measuring G4P and GTP in these organisms, and we hope will accelerate research into the function of G4P signaling in plants, algae and other organisms.

The results generated in this study also raise interesting questions about the relationship between G4P and GTP, and the regulation of G4P biosynthesis in algae. In many bacteria G4P accumulation causes a drop in GTP levels. This can occur via the consumption of GTP, or via the direct inhibition of enzymes in the GTP biosynthesis pathway by G4P (Liu et al., 2015). We observed that OX:RSH3 plants have much higher G4P levels than the wild type control, yet do not have significantly altered GTP content. GTP does not freely exchange between the chloroplast and cytosol (Kusumi and Iba, 2014; Olsen and Keegstra, 1992). Therefore, if we assume that the chloroplast compartment makes a substantial contribution to the cellular GTP pool, then our results indicate that G4P does not inhibit GTP production in the chloroplast in OX:RSH3 plants. This result is somewhat surprising because G4P has been shown to specifically inhibit the chloroplastic guanylate kinase, an enzyme necessary for GTP production in the chloroplast (Nomura et al., 2014).

We also observed only a very small increase in G4P levels in Chlamydomonas following dark treatment. This dark-induced G4P increase is substantially smaller than the 4-6-fold dark-induced increase in G4P that is observed in Arabidopsis and which is dependent on the Ca2+ activated G4P synthase CRSH (Ihara et al., 2015; Ono et al., 2019). A CRSH homologue is also present in C. reinhardtii. Our G4P measurements might suggest that there are differences in the strength of CRSH activation in response to darkness between Arabidopsis and $C$. reinhardtii. However, it is also possible that during the preparation of the cells the centrifugation steps, which occur in darkness, cause an increase in G4P in the control sample that masks the increase in the dark-treated cells. Further studies will be required to establish for certain whether dark can induce G4P accumulation. 
Finally, we note that our method still has room for improvements. In particular, the HPLC separation approach used here prior to MS/MS detection relies on the ion-pairing reagent DMHA to retain the highly polar nucleotides on a reverse phase $\mathrm{C} 18$ chromatography column. Ion-pairing reagents such as DMHA can be problematic for HPLC-MS systems as they cannot be easily removed from columns and plastic tubing, and sometimes require long equilibration times (Yerneni, 2017). Notably, there are recent examples of the successful separation of G4P and other nucleotides from both bacteria and algae using hydrophilic interaction (HILIC) chromatography (Jin et al., 2018; Zborníková et al., 2019).

\section{Acknowledgements}

The authors thank Julie Viala for support in the lab and Yasmine Hassoun for the construction of the GppA expression plasmid. The work was funded by Agence Nationale de la Recherche (ANR-17-CE130005) and the IJPB benefits from the support of Saclay Plant Sciences-SPS (ANR-17-EUR-0007).

\section{Contributions}

B.F and E.B conceived the experiments. J.B prepared labelled G4P, J.B and B.F performed nucleotide extractions and S.C and G.M setup the HPLC-MS/MS separation method and quantified nucleotides. J.B, S.C, G. M, E. B and B.F contributed to the analysis and interpretation of the results. B.F and E.B wrote the manuscript. All authors provided critical feedback and helped shape the research, analysis and manuscript.

\section{Table 1}

\begin{tabular}{lccccc} 
Compound & Precursor & Fragment & Collision energy, $\mathrm{mV}$ & LOD, $\mathrm{pmol} \mathrm{g}$ & LOQ, pmol g \\
\hline 13C-GTP & 532 & 159 & 35 & 6.3 & 20.7 \\
GTP & 522 & 159 & 35 & 6.3 & 20.7 \\
13C-G4P & 612 & 159 & 22 & 1.9 & 6.2 \\
G4P & 602 & 159 & 22 & 1.9 & 6.2
\end{tabular}




\section{Figure legends}

Figure 1. Synthesis and isolation of stable-isotope labelled G4P and G5P. (A) Outline of reaction scheme for the synthesis of isotope-labelled nucleotides. (B) Separation of reaction products by ion-exchange HPLC from control reactions where no enzyme was added, and from reactions where the indicated enzymes were included. (C) Validation of isolated nucleotides by detection of daughter ions following the collision induced ionization of $13 \mathrm{C}-\mathrm{G} 5 \mathrm{P}$ and $13 \mathrm{C}-\mathrm{G} 4 \mathrm{P}$ [M-H]- parental ions.

Figure 2. A procedure for the quantification of nucleotides in bacteria, plants and algae. (A) Outline of the extraction procedure with stable-isotope label internal standards. 1, formic acid containing stableisotope labeled (SIL) internal standards (IS)(red circles) is prepared; 2, biological samples containing unlabeled endogenous nucleotides (violet circles) are added; 3 , nucleotides are enriched using an Oasis weak-anion exchange (WAX) solid phase extraction (SPE) cartridge; 4, nucleotides are eluted and lyophilized; and 5, nucleotides are injected into an HPLC-MS/MS system for analysis and quantification. (B) The procedure for the extraction and quantification of G4P was validated on late exponential phase bacterial cells from a wild type strain (WT), a strain lacking G4P and G5P (G4P/G5P $)$, and a strain overaccumulating G4P $\left(\mathrm{G} \mathrm{P}^{+}\right)$. Means $+/-\mathrm{SE}$ are indicated, $\mathrm{n}=4$ biological replicates.

Figure 3. Quantification of GTP and G4P in plants and algae. (A) GTP and G4P were quantified in the leaves of 4 week old Arabidopsis plants using 13-GTP and 13C-G4P internal standards. Means +/- SE are indicated, $n=4$ biological replicates. (B) GTP and G4P were quantified in Chlamydomonas cells grown under normal conditions (light) or transferred to darkness for $1 \mathrm{hr}$ (dark) using using 13-GTP and 13CG4P internal standards. Means $+/$ - SE are indicated, $n=4$ biological replicates.

Figure S1. Purification of Relseq and GppA. Coomassie Brilliant Blue stained SDS-PAGE gels showing the purification steps for the purification of (A) RelSeq and (B) GppA. T, total extract; S, soluble extract; FT, flow through; E1-E5, elution fractions; L, size marker ladder; and $\mathrm{P}$, insoluble pellet. 


\section{References}

Buckstein, M.H., He, J., and Rubin, H. (2008). Characterization of Nucleotide Pools as a Function of Physiological State in Escherichia coli. J. Bacteriol. 190: 718-726.

Corrigan, R.M., Bellows, L.E., Wood, A., and Grundling, A. (2016). ppGpp negatively impacts ribosome assembly affecting growth and antimicrobial tolerance in Gram-positive bacteria. Proc Natl Acad Sci U A 113: E1710-9.

Field, B. (2018). Green magic: regulation of the chloroplast stress response by (p)ppGpp in plants and algae. J. Exp. Bot. 69: 2797-2807.

Hernandez, V.J. and Bremer, H. (1991). Escherichia coli ppGpp synthetase II activity requires spoT. J Biol Chem 266: 5991-9.

Hung, W.-F., Chen, L.-J., Boldt, R., Sun, C.-W., and Li, H. (2004). Characterization of Arabidopsis Glutamine Phosphoribosyl Pyrophosphate Amidotransferase-Deficient Mutants. Plant Physiol. 135: 1314-1323.

Ihara, Y., Ohta, H., and Masuda, S. (2015). A highly sensitive quantification method for the accumulation of alarmone ppGpp in Arabidopsis thaliana using UPLC-ESI-qMS/MS. J Plant Res 128: 511-8.

Jin, H., Lao, Y.M., Zhou, J., Zhang, H.J., and Cai, Z.H. (2018). A rapid UHPLC-HILIC method for algal guanosine 5'-diphosphate 3'-diphosphate (ppGpp) and the potential separation mechanism. J. Chromatogr. B Analyt. Technol. Biomed. Life. Sci. 1096: 143-153.

Kusumi, K. and Iba, K. (2014). Establishment of the chloroplast genetic system in rice during early leaf development and at low temperatures. Front. Plant Sci. $\mathbf{5}$.

Li, X., Zhang, R., Patena, W., Gang, S.S., Blum, S.R., Ivanova, N., Yue, R., Robertson, J.M., Lefebvre, P.A., Fitz-Gibbon, S.T., Grossman, A.R., and Jonikas, M.C. (2016). An Indexed, Mapped Mutant Library Enables Reverse Genetics Studies of Biological Processes in Chlamydomonas reinhardtii. Plant Cell 28: 367-87.

Maciag, M., Kochanowska, M., Lyzen, R., Wegrzyn, G., and Szalewska-Palasz, A. (2010). ppGpp inhibits the activity of Escherichia coli DnaG primase. Plasmid 63: 61-7.

Macvanin, M., Johanson, U., Ehrenberg, M., and Hughes, D. (2000). Fusidic acid-resistant EF-G perturbs the accumulation of ppGpp. Mol. Microbiol. 37: 98-107.

Mechold, U., Potrykus, K., Murphy, H., Murakami, K.S., and Cashel, M. (2013). Differential regulation by ppGpp versus pppGpp in Escherichia coli. Nucleic Acids Res 41: 6175-89.

Murray, K.D. and Bremer, H. (1996). Control of spoT-dependent ppGpp synthesis and degradation in Escherichia coli. J Mol Biol 259: 41-57. 
My, L., Rekoske, B., Lemke, J.J., Viala, J.P., Gourse, R.L., and Bouveret, E. (2013). Transcription of the Escherichia coli fatty acid synthesis operon fabHDG is directly activated by FadR and inhibited by ppGpp. J Bacteriol 195: 3784-95.

Nomura, Y., Izumi, A., Fukunaga, Y., Kusumi, K., Iba, K., Watanabe, S., Nakahira, Y., Weber, A.P., Nozawa, A., and Tozawa, Y. (2014). Diversity in Guanosine 3',5'-Bisdiphosphate (ppGpp) Sensitivity Among Guanylate Kinases of Bacteria and Plants. J Biol Chem.

Olsen, L.J. and Keegstra, K. (1992). The binding of precursor proteins to chloroplasts requires nucleoside triphosphates in the intermembrane space. J Biol Chem 267: 433-9.

Ono, S., Suzuki, S., Ito, D., Tagawa, S., Shiina, T., and Masuda, S. (2019). Plastidial (p)ppGpp synthesis by the Ca2+-dependent RelA-SpoT homolog regulates the adaptation of chloroplast gene expression to darkness in Arabidopsis. bioRxiv: 767004.

Patacq, C., Chaudet, N., and Létisse, F. (2018). Absolute Quantification of ppGpp and pppGpp by DoubleSpike Isotope Dilution Ion Chromatography-High-Resolution Mass Spectrometry. Anal. Chem. 90: 10715-10723.

Ronneau, S. and Hallez, R. (2019). Make and break the alarmone: regulation of (p)ppGpp synthetase/hydrolase enzymes in bacteria. FEMS Microbiol. Rev. 43: 389-400.

Slomińska, M., Neubauer, P., and Wegrzyn, G. (1999). Regulation of bacteriophage lambda development by guanosine 5'-diphosphate-3'-diphosphate. Virology 262: 431-441.

Stokvis, E., Rosing, H., and Beijnen, J.H. (2005). Stable isotopically labeled internal standards in quantitative bioanalysis using liquid chromatography/mass spectrometry: necessity or not? Rapid Commun. Mass Spectrom. 19: 401-407.

Sugliani, M., Abdelkefi, H., Ke, H., Bouveret, E., Robaglia, C., Caffarri, S., and Field, B. (2016). An Ancient Bacterial Signaling Pathway Regulates Chloroplast Function to Influence Growth and Development in Arabidopsis. Plant Cell 28: 661-79.

Svitil, A.L., Cashel, M., and Zyskind, J.W. (1993). Guanosine tetraphosphate inhibits protein synthesis in vivo. A possible protective mechanism for starvation stress in Escherichia coli. J Biol Chem 268: 2307-11.

Takahashi, K., Kasai, K., and Ochi, K. (2004). Identification of the bacterial alarmone guanosine 5'diphosphate 3'-diphosphate (ppGpp) in plants. Proc Natl Acad Sci USA 101: 4320-4.

Varik, V., Oliveira, S.R.A., Hauryliuk, V., and Tenson, T. (2017). HPLC-based quantification of bacterial housekeeping nucleotides and alarmone messengers ppGpp and pppGpp. Sci. Rep. 7.

Wahl, A., My, L., Dumoulin, R., Sturgis, J.N., and Bouveret, E. (2011). Antagonistic regulation of dgkA and plsB genes of phospholipid synthesis by multiple stress responses in Escherichia coli. Mol Microbiol 80: 1260-75. 
bioRxiv preprint doi: https://doi.org/10.1101/2019.12 13.875492; this version posted January 23,2020 . The copyright holder for this preprint

(which was not certified by peer review) is the author/funder, who has granted bioRxiv a license to display the preprint in perpetuity. It is made available under aCC-BY-NC 4.0 International license.

Yang, Z., Shang, Z., Wang, L., Lu, Q., Wen, X., Chi, W., Zhang, L., and Lu, C. (2015). Purine biosynthetic enzyme ATase 2 is involved in the regulation of early chloroplast development and chloroplast gene expression in Arabidopsis. Photosynth. Res. 126: 285-300.

Yerneni, C. (2017). Ion Pair Chromatograpy: A Critical Prespective. J. Anal. Pharm. Res. 4.

Zborníková, E., Knejzlík, Z., Hauryliuk, V., Krásný, L., and Rejman, D. (2019). Analysis of nucleotide pools in bacteria using HPLC-MS in HILIC mode. Talanta 205: 120161. 